\title{
The Napster moment: Access and innovation in academic publishing
}

\author{
Kendall Bartsch \\ CEO, Third Iron, LLC, P.O. Box 27400, St Paul, MN 55127, USA \\ E-mail: kendall@thirdiron.com
}

Abstract. The music industry stands as a case study in how digital access to information changes user expectations and, because of these changes in expectations, innovation in access is necessary for an industry to survive and thrive. This paper discusses these changes and how they apply in understanding the current state of scholarly publishing; how change in access to licensed content is needed; and that a plurality of access modes will likely arise as a result.

Keywords: Napster, academic publishing, access, RA21, licensed content

\section{Introduction}

The 1990's music service, Napster, has become a metaphor for the remarkable transformation it triggered in the music and recording industry. Although the original Napster existed as a company for just a short time, its technology quickly changed consumer expectations about how music ought to be delivered and, as a result, forced the music industry to change how music was produced and distributed.

This paper explores how this history of transformation in the music industry, spurred by Napster, mirrors changes that are underway in how access to licensed content is managed in the academic publishing industry.

\section{Digital music}

In 1982 while at the University of Erlangen-Nuremburg, PhD student, Karlheinz Brandenburg was given a challenge by his graduate advisor: find a way to transmit music on ISDN phone lines. It was through work on solving this problem that the MP3 digital file format was created. Although Brandenburg did not know it at the time, his work was the first step in a number of events that would significantly change how music was consumed and distributed.

Bandwidth limitations of phone lines, even relatively high bandwidth lines like ISDN, meant that solving this problem would require decreasing the size of a music file. Brandenburg's breakthrough came through taking advantage of an aspect of human hearing called auditory masking, a phenomenon where the human ear is unable to hear certain competing sounds. For example, louder sounds or those with lower frequencies often mask other sounds, making these sounds essentially inaudible. Brandenberg was able to isolate these masked sounds and discard them during the digital recording process, thereby reducing the size of the music file, all while having no discernable loss in sound quality. 
By the late 1990s, a number of companies were working on different ways to digitize audio and video content. To create standardization across these formats, the International Organization for Standardization assembled a team in 1998 called the Moving Pictures Experts Group, or MPEG. Most of Brandenberg's ideas about compressing audio to deliver the best sound resolution at low bitrates were in what the MPEG designated as the third layer, or what became commonly known as MP3.

With the MP3 format established and music increasingly-available in this format, users could save MP3 files to the hard drives of their computers. Pioneering companies saw the opportunity to liberate MP3 files from the computer and in the late 1990's a quick succession of portable MP3 players were introduced. Among the earliest players were Audio Highway's Listen Up MP3 player which was released in 1997, followed in 1998 by the MPMan player from Seahan Information Systems. These first devices were rudimentary, had limited battery life, and were able to hold just a handful of songs. It has been reported that only 25 Listen Up players were produced, suggesting it was more proof-of-concept than real product.

The Rio portable MP3 player was introduced in 1998 by Diamond Multimedia Systems and was the first device to start the dramatic expansion of the digital player market. This was not because it employed a breakthrough technology, but because of the lawsuit its introduction triggered.

The Recording Industry Association of America (RIAA) brought suit against Diamond arguing that the Audio Home Recording Act of 1992 did not permit the sort of digitization of music and device transfer that the Rio facilitated because the Rio did not "employ a Serial Copyright Management System ('SCMS') that sends, receives, and acts upon information about the generation of copyright status for the file it plays". ${ }^{1}$ The RIAA was concerned that the Rio and similar devices would allow individuals to create second-generation, or "serial," copies of the original music which could then be easily passed on to others.

The court ruled against the RIAA. Crucially, the court ruling indicated that the noncommercial copying of recorded files from a computer hard drive to the Rio memory was fair use. As the ruling read, "In fact, the Rio's operation is entirely consistent with the Act's main purpose - the facilitation of personal use. The Rio merely makes copies in order to render portable, or 'space shift,' those files that already reside on a user's hard drive". ${ }^{2}$

With standards for music digitization created, and a court ruling that cleared the way for individuals to digitize and export music files, the stage was set for rapid changes.

\section{Rise of music sharing}

While the development of MP3 files allowed individuals to create, organize and listen to digital music, it was difficult to share music with others, even while other information was easily shared over the fast growing internet. Alex Winter, the director of the documentary film Downloaded, remarked how, in the early days of the internet, finding and downloading music was "a colossal pain" where people would "spend 14 hours trying to pull a song offline, only to have it fail. They would try again. And it would fail" [3].

This disconnect between the massive amounts of digital music, the great potential to share it over the internet, and the limited ability to do so, was not lost on users. Around 1998 Shawn Fanning developed peer-to-peer software to bypass the problem. This software, called Napster, created a central index of

\footnotetext{
${ }^{1}$ Audio Home Recording Act (AHRA) 17 U.S.C. $\$ 10011992$.

${ }^{2} 180$ F.3d at 1079 (see: https://www.law.cornell.edu/copyright/cases/180_F3d_1072.htm).
} 
music files contained on the hard drives of everyone using the software, along with a process to access and download the music files over the internet. Suddenly, finding and downloading music was easy and free.

Fanning and his partner, Sean Parker, saw the opportunity. They founded the company Napster in May 1999 to promote the development and distribution of their software. It soon became wildly popular. By February 2001, not even two years after the initial founding of the company, global users peaked at 25.4 million [8]. As technologist John Perry Barlow related, "It's difficult to describe to people... how much material was suddenly available" [3]. Winters noted, "There was no ramp-up. There was no transition. It was like that famous shot from 2001: A Space Odyssey, when the prehistoric monkey throws a bone in the air and it turns into a spaceship. Napster was a ridiculous leap forward" [3]. It is well-known that the rapid rise of Napster was followed by an equally spectacular end: in July 2001, following a successful lawsuit filed by RIAA claiming Napster infringed copyright, Napster ceased operations.

While Napster had a short life, it showed that digital music could be shared without friction: it could be obtained quickly, easily, and at no cost. This break from the previously cumbersome process of acquiring music fundamentally shaped consumer expectations about how music could and should be delivered - users expected a Napster-like experience when consuming music. Moreover, it exposed a willingness among many to use non-commercial means to obtain music if expectations were not met. The music industry has been working ever since to innovate delivery mechanisms that conform to these expectations.

\section{Responsive innovation}

Steve Jobs in 2001 made the first significant step into the Napster vacuum with iTunes. Jobs bet that if a superior technology ecosystem could be created that allowed people to download songs cheaply and easily, licensed downloads could compete with free illegal downloads. The iTunes bet has been paying off for Apple and the recording industry ever since.

Pandora, released in 2005, was the first major music streaming service. Other steaming services have also emerged, including Spotify in 2008, Beats in 2012, and iHeartRadio in 2015. While these streaming services are still working through important aspects of their business models, such as refining monetization strategies and royalties paid to artists, they have quickly expanded their user base and are generating revenue, both for themselves and the music industry. For example, in 2010, just two years after launch, Spotify reported they were making more money for music companies in their home country of Sweden than what these music companies were earning from any other retailer.

Beyond music downloads and streaming services, innovation in commercial music delivery continues. Music.ly, Snapchat, and Instagram are three examples. These services are not the traditional ways we envision how people listen to music, but music is being blended into the social engagement they provide and monetized by the recording industry.

With Musical.ly, a social video sharing app launched in 2014, people can create and upload fifteen second videos of themselves dancing and singing along to a huge catalog of songs available in the app. Musical.ly reported in 2016 over ninety million users globally, up from ten million the year before. Warner Music was the first to sign a deal licensing its music to the app, with Sony Music quickly following.

Following Napster, and during the years of innovating delivery models, recording industry revenues largely declined. 2015, however, marked a turning point. As summarized in the Global Music Report 
2016, the year 2015 included key milestones for recorded music, including digital revenues overtaking income from physical formats, measureable revenue growth increasing 3.2\%, and streaming consumption increasing nearly $100 \%$ from the previous year in the United States [4, p. 8]. Frances Moore, the CEO of the International Federation of the Phonographic Industry, wrote in the Global Music Report that reaching these milestones did "not happen by accident." Rather, "it is the result of tireless work and adaptation. Record companies have quite simply transformed to survive and thrive. They have embraced all forms of digital distribution, giving consumers ever-expanding choices of music offerings" [4, p. 5].

\section{Digital scholarship expectations}

The evolution of academic journal creation and distribution parallels the transformation of digital music delivery and suggests changes ahead. Specifically, how digitization of content dramatically increases the potential for access; how barriers to access have led to informal and illicit sharing of licensed information; how the easy access of sharing has shaped user expectations; and how the publishing industry is innovating to preserve their business while meeting these new expectations.

When print academic journals were digitized, it was similar to when music became digital: an immense amount of content became instantly available and could be accessed from anywhere. Anyone who did research during this transition can attest to the effect: moving from manually recording notes taken from print indexes then hunting the library stacks, to searching on platforms such as Science Direct was transformative.

There is nothing to physically check out with a digital resource, so access to this licensed content was, and continues to be, largely regulated by IP address. In subscribing to digital resources, libraries record IP ranges with publishers and restrict access to people on devices from within this IP range. Remote access technologies developed to support off-site access such as proxy servers and VPN systems are essentially extensions of IP authentication. Provided researchers are on site, or if working remotely they started their information discovery process from their library portal, access to resources is magical: all institutional resources are just a click away. This frictionless access to information has created Napsterlike expectations among researchers.

But as scholarly articles became indexed in services like CiteSeer, Scirus, and Google Scholar, a new problem was introduced. When using these services from outside their institutions' IP range, it became common for researchers to find articles they needed, but then face a frustratingly confusing access scheme or be unexpectedly confronted with a paywall for content. Users that were otherwise used to easily downloading information were now being denied access.

Estimating how many access requests are denied at a publisher site is challenging. The 2015 STM report indicates that 2.5 billion articles are downloaded annually [7]. In 2012, JSTOR reported in the Chronicle of Higher Education that almost one hundred and fifty million individual attempts to gain access to articles were turned away [2]. Assuming, based on size of collections, that JSTOR represents approximately $1.5 \%$ of the total full text article requests across publishers, and that the JSTOR turn-away rate is representative of other publishers, then there are twelve billion requests turned way annually by publishers.

When denied access to content they want, researchers try for access in other ways, turning to peer-topeer transfer via email, social media, community websites, and illegal services developed for the explicit purpose of providing free and simple access to articles. 


\section{Academic sharing ecosystem}

Most sharing of academic material is done by email. When faculty and students cannot find access to an item of interest, they simply ask their colleagues for a copy. This is usually the first solution sought by researchers when they encounter barriers to information, and it is estimated that for every one article that is downloaded, eleven are shared via email [1, p. 132].

Emerging social media sites like Academia.edu and Researchgate.net allow users to upload and download papers. While these sites police how copyrighted material is uploaded and shared by taking offending items down, or requiring users interested in obtaining a copy to contact the author, copyrighted materials are still found available for download. For example, as of this writing on May 18, 2017, a search in Academia.edu for the article "Brothers in Sound: Koffi Kwahule and Jazz (Interviews with Gilles Mouëllic)" reveals that it is free to download, but is otherwise behind a paywall on Project Muse.

The hash tag \#icanhazpdf was coined in 2011 as way for Twitter users to broadcast an article request to like-minded researchers. People will usually list the citation of the paper wanted, then add the hash tag, often including an email address. Other Twitter users following the hash tag, if they have access to the article, will share it via email or by uploading it to a public folder on cloud services like Dropbox. Tweets are then routinely deleted after the paper is delivered to avoid duplication.

Reddit Scholar is a subgroup of the popular Reddit service created in 2009. It grew to twenty thousand users by 2014 with people using it to solicit request for papers or book chapters [1, p. 134]. Members of the subgroup who see requests use their personal access to download the item and share it, like with \#icanhazpdf, either by emailing it or uploading it to a cloud service like Dropbox where the link is then shared.

SciHub is perhaps the most notorious service. An online repository created by the Kazakh graduate student, Alexandra Elbakyan, SciHub reportedly contains a growing catalog of over fifty-eight million articles and book chapters that anyone may freely-download. Once going to the SciHub site, users simply input the DOI of the article or search by keyword and get immediate access to the PDF. In 2015 Elsevier filed a complaint against SciHub claiming copyright infringement and the original site, Sci-Hub.org, was suspended. However, mirror sites quickly resurfaced under alternate domain names and access continues to be available.

These alternative mechanisms for providing access to articles have emerged because researchers do not have authorized access to material and do not want to pay for it; or they are entitled to access, but either fail to understand the process required to obtain it; or they prefer not to use the processes required for access.

\section{Innovation in access}

The number of access denials, the user expectation for seamless access, and the spread of technologies which provide alternative - and often illegal - access, are issues not lost on the publishing industry. Mirroring the experience of the music industry, new initiatives are underway to provide better access that meet user expectations.

RA21: Resource Access in the 21st Century was established in 2016 as a joint initiative between the STM Association and the National Information Standards Organization. RA21 broadly aims to "optimize protocols across key stakeholder groups, with the goal of facilitating a seamless user experience for consumers of scientific communication" [6]. Moreover, RA21 will work to "solve long-standing, complex, and broadly distributed challenges in the area of network security and user privacy" [6]. 
In early 2017, RA21 created pilot programs steered by working groups to explore how SAML and Shibboleth technologies can be extended and applied to accomplish these goals. The intention is for the outcome of these pilots to be reported to the RA21 group in late 2017, with recommendations to be made and formalized that may then be developed into a common technology solution adopted by publishers, universities, and other institutions.

Similarly, Highwire Press, in conjunction with Google, is developing a program called CASA that aims to achieve goals similar to those of RA21, specifically seamless access to licensed content found in Google Scholar. Preliminary information indicates CASA uses a browser token system to establish user identity, then uses this token to authenticate access to articles found in Google Scholar when the user is off site [5].

RA21 and CASA are just the start of innovations forced by the pressure of consumer expectations, themselves created by the promise of digital access. Like the music industry, we can expect there will be additional solutions that come to market and in the end, a plurality of technologies available to end users that deliver scholarly content in a way that satisfies expectations.

\section{About the author}

Kendall Bartsch is the CEO and Co-founder of Third Iron, LLC, a technology company devoted to innovating software solutions for libraries and their users. He received his Bachelor of Arts from Drake University and a Master of Arts from University of Iowa.

\section{References}

[1] C. Caffrey Gardner and G. Gardner, Fast and furious (at publishers): The motivations behind crowdsourced research sharing, College \& Research Libraries 78(2) (2017), 131-149.

[2] J. Howard, JSTOR tests free, read-only access to some articles, Chronicle of Higher Education [Internet], January 13, 2012 [cited 2017 May 18]. Available from: http://www.chronicle.com/blogs/wiredcampus/jstor-tests-free-read-only-accessto-some-articles/34908.

[3] T. Lamont, Napster: The day the music was set free, The Guardian [newspaper on the internet], February 23 (2013) [cited 2017 May 18]. Available from: https://www.theguardian.com/music/2013/feb/24/napster-music-free-file-sharing.

[4] F. Moore, Global Music Report, Music Consumption exploding worldwide (2016) [cited June 14, 2017], Sponsored by International Federation of the Phonographic Industry (see http://www.ifpi.org/downloads/GMR2016.pdf).

[5] J. Stack, Mobile discovery and mobile use of scholarly content, Webinar sponsored by NFAIS, 2017.

[6] STM [Internet], [Cited 2018 May 18]. Standards \& Technology; [First screen]. Available from http://www.stm-assoc.org/ standards-technology/ra21-resource-access-21st-century/.

[7] M. Ware and M. Mabe, The STM report: An overview of scientific and scholarly journal publishing, 4th edn, 2015, p. 180.

[8] A. Winter, The short history of Napster 1.0, Wired [Internet], April 4 (2013) [cited 2017 May 18]. Available from: https:// www.wired.com/2013/04/napster/. 